\title{
Erratum to: Polarization measurement for ordinal data
}

\section{Martyna Kobus ${ }^{1}$}

Published online: 30 June 2015

(C) Springer Science+Business Media New York 2015

\section{Erratum to: J Econ Inequal DOI 10.1007/s10888-014-9282-y}

Unfortunately the original version of the paper did not include the detailed funding information below:

Funding: This work was supported by the National Science Centre, Poland, grant 2013/09/D/HS4/01029. 